\title{
PENGALAMAN KARIES GIGI SERTA POLA MAKAN DAN MINUM PADA ANAK SEKOLAH DASAR DI DESA KIAWA KECAMATAN KAWANGKOAN UTARA
}

\author{
${ }^{1}$ Indry Worotitjan \\ ${ }^{2}$ Christy N. Mintjelungan \\ ${ }^{3}$ Paulina Gunawan
}

\author{
${ }^{1}$ Kandidat skripsi Program Studi Kedokteran Gigi Fakultas Kedokteran \\ Universitas Sam Ratulangi Manado \\ ${ }^{2}$ Bagian Ilmu Kesehatan Gigi Masyarakat Program Studi Kedokteran Gigi Fakultas \\ Kedokteran Universitas Sam Ratulangi Manado \\ ${ }^{3}$ Bagian Ilmu Kedokteran Gigi Anak Program Studi Kedokteran Gigi Fakultas Kedokteran \\ Universitas Sam Ratulangi \\ Email: indry_inLovewithGod@yahoo.com
}

\begin{abstract}
Dental caries is an infectious disease resulting email and dentin demineralization. In general, children enter school age have a high caries risk, because at this school age children have a habit of eating foods and beverages cariogenic. This research is descriptive. The purpose of this study was to determine the dental caries experience and patterns of eating and drinking in primary school children in rural North Kawangkoan Kiawa District.The entire study population the sixth grade elementary school students in the village of North KawangkoanKiawa district totaling 60 samples were taken using the Total Sampling. Data retrieval of primary dental caries examination to see the number of dental caries experience (DMF-T) and filling out the questionnaire by using Food Frequency Questionnaire (FFQ) to see the pattern of eating and drinking in primary school children in rural North Kawangkoan Kiawa District.The results showed that primary school students in desaKiawahaving caries experience caries being the average DMF-T 3.71 it means each one of childrens having four caries teeth. Diet on elementary school children who consumed foods cariogenic carbohydrate snack at a frequency that is the most time 2-3 times per day and drinking patterns in elementary school children who consume isotonic drinks cariogenic ie at a frequency of 1-3 times per week.
\end{abstract}

Keywords: dental cariesexperience, eating patterns and drinking, elementary school children.

\begin{abstract}
Abstrak:Karies gigi merupakan penyakit yang disebabkan oleh demineralisasi email dan dentin. Anak-anakmemasuki usia sekolah umumnya mempunyai resiko terhadap karies yang tinggi, karena pada usia ini anak-anak memiliki kebiasaan mengonsumsi makanan dan minuman kariogenik. Penelitian ini merupakan penelitian deskriptif. Tujuan penelitian ini ialah untuk mengetahui pengalaman karies gigi serta pola makan dan minum pada anak sekolah dasar di desa Kiawa kecamatan Kawangkoan Utara.Populasi penelitian yaitu seluruh murid SD kelas VI di desa Kiawa Kecamatan Kawangkoan Utara yang berjumlah 60 sampel diambil dengan menggunakan metode total sampling. Pengambilan data primer yaitu pemeriksaan karies gigi untuk melihat jumlah pengalaman karies gigi (DMF-T) dan pengisian kuesioner dengan menggunakan Food Frequency Questionnaire (FFQ) untuk melihat pola makan dan minum pada anak sekolah dasar di desa Kiawa kecamatan Kawangkoan Utara.Hasil penelitian menunjukkan bahwa siswa sekolah dasar didesaKiawamemilikipengalaman karies gigikategori sedang dengan rata-rata DMF-T 3.71 yang artinya anak-anak sekolah mengalami karies ratarata 4 gigi. Pola makan makanan karbohidrat kariogenik tertinggi pada anak sekolah dasar yaitu snackpada frekuensi waktu 2-3 kali per hariPola minum minumankariogenik tertinggi pada anak sekolah dasar yaitu minuman isotonik pada frekuensi 1-3 kali per minggu.
\end{abstract}

Kata kunci: pengalaman karies gigi, pola makan dan minum, anak sekolah dasar. 
Gigi merupakan bagian dari alat pengunyahan pada sistem pencernaan dalam tubuh manusia. ${ }^{1}$ Masalah utama kesehatan gigi dan mulut anak ialah karies gigi. Penyakit gigi yang sering diderita oleh hampir semua penduduk Indonesia ialah karies gigi. ${ }^{2}$ Riset kesehatan dasar (Riskesdas) tahun 2007 menyebutkan bahwa prevalensi karies aktif di Indonesia sebesar 46,5\%. Menurut data Riskesdas tahun 2007, provinsi Sulawesi Utara memiliki indeks DMF-T 5.01. ${ }^{3}$

Karies gigi merupakan penyakit infeksi yang disebabkan olehdemineralisasi email dan dentinyang erat hubungannya dengan konsumsi makanan yang kariogenik. Terjadinya karies gigi akibat peran dari bakteri penyebab karies yang terdapat pada golongan Streptokokus mulut yang secara kolektif disebut Streptokokus mutans. ${ }^{5}$

Umumnya anak-anak memasuki usia sekolah mempunyai resiko karies yang tinggi, karena pada usia sekolah ini anakanak biasanya suka jajan makanan dan minuman sesuai keinginannya. Pemilihan anak-anak kelas VI sebagai sampel dikarenakan anak-anak kelas VI rata-rata berusia 10-11 tahun. Anak-anak pada usia ini rentan terhadap pertumbuhan dan perkembangan karies gigi karena memiliki kebiasaan jajan makanan dan minuman baik di sekolah maupun di rumah.Berdasarkan hal tersebut peneliti tertarik melakukan penelitian pada anak-anak sekolah dasar kelas VI, usia 10-11 tahun di desa Kiawa Kecamatan Kawangkoan Utara Kabupaten Minahasa. Hal ini didukung juga karena sekolah-sekolah dasar di desa Kiawa berdasarkan hasil survei yang dilakukan peneliti sebelumnya tidak memiliki Usaha Kesehatan Gigi Sekolah (UKGS). Sekolahsekolah dasar di desa Kiawa ini juga belum pernah dilakukan penelitian mengenai karies dan penyuluhan kesehatan Gigi dan Mulut.

\section{METODE PENELITIAN}

Penelitian yang dilakukan yaitu penelitian deksriptif dengan menggunakan pendekatan desain penelitian cross sectionalstudy ${ }^{16}$. Penelitian inidilakukan di desa Kiawa Raya Kecamatan Kawangkoan
Utara terdiri dari 4 sekolah dasar yang di laksanakan pada bulanSeptember 2012. Populasi pada penelitian yaitu seluruh anak sekolah dasar kelas VIdi SD GMIM I, SD GMIM II, SD Katolik dan SD Negeri Inpres yang rata-rata berusia 10-11 tahun di desa Kiawadengan jumlah populasi 60 orang. Sampelpada penelitian ini ialahanak-anak sekolah dasarkelas VI yang terdaftar dan aktif sebagai murid SD di desa Kiawa yang memenuhi kriteria inklusi dan eksklusi. Kriteria inklusi yaitu sampel bersedia secara sukarela dan telah mendapatkan ijin dari orang tua mengikuti penelitian ini secara penuh dan sebagai subyek penelitian melalui informed consent, bersifat kooperatif selama pengambilan data. Kriteria eksklusi yaitu anak-anak sekolah dasar di desa Kiawayang bersedia sebagai subyek penelitian namun tidak berada di tempat saat dilakukan penelitian karena ijin atau sakit dan anakanak sekolah periode gigi bercampur.

Teknik pengambilan sampel dengan menggunakan teknik Total Sampling. Seluruh populasi menjadi sampel pada penelitian ini dengan besar sampel yaitu 60 anak sekolah. Variabel penelitian yaitu pengalaman karies gigi dan pola makan dan minum.Definisi operasional variable pengalaman karies gigi yaitu karies pada anak-anak sekolah dasar yang dinyatakan melalui perhitungan menggunakan indeks DMF-T. Indeks DMF-T adalah angka yang menyatakan adanya karies gigi (decayed), kehilangan gigi(missing) dan tumpatan (filling) pada seluruh gigi permanen.

Rerata DMF-T adalah jumlah seluruh nilai DMF dibagi atas jumlah orang yang diperiksa:

$$
\text { DMF }-\mathbf{T}=\frac{\text { Jumlah } \mathbf{D}+\mathbf{M}+\mathbf{F}}{\text { Jumlah orang yang diperiksa }}
$$

Kategori dalam perhitungan DMF-T berdasarkan $\mathrm{WHO}^{6}$; Sangat rendah $(0,0-$ $1,1)$; rendah (1,2-2,6); sedang (2,7-4,4); tinggi $(4,5-6,5)$; Sangat Tinggi $(>6,6)$.

Pola makan dan minum yaitu kebiasaan makan dan minum anak-anak sekolah dasar kelas VI usia 11-12 tahun yang diketahui melalui wawancara menggunakan Food 
Frequency Questionaire (FFQ) untuk melihat jenis makanan dan minuman, serta frekuensi kebiasaan makan setiap hari (per hari) dan setiap minggu (per minggu). Food Frequency Questionaire (FFQ) terdiri dari:

1. Jenis makanan karbohidrat non kariogenik seperti nasi, jagung, mie instan, kentang, ubi jalar, singkong, sayuran, kacang-kacangan dan buah-buahan. Makanan kariogenik yaitu roti, kue, permen, coklat, snack.

2. Jenis minuman yaitu minuman murni (non kemasan) dan minuman kemasan. Minuman murni seperti susu murni, teh murni, kopi murni, sirup murni, jus buah murni yaitu minuman yang dibuat secara sederhana, dalam skala rumah tangga. Minuman kemasan seperti susu kemasan, teh kemasan, kopi kemasan, sirup kemasan dan jus buah kemasan yaitu minuman yang dikemas, dapat diminum secara langsung tanpa melalui proses pembuatan terlebih dahulu.

Instrumen yang digunakan pada penelitian ini yaituFormulirpemeriksaan DMFT,Food frequency questionaire, 2 kaca mulut, sonde, pinset, sarung tangan dan masker, nierbeken, sterilisasi: air mineral, sabun cairantiseptik, alkohol $70 \%$ dan wadah, alat tulis menulis, tisu kering. Pengolahan data dan analisis data diolah berdasarkandistribusi frekuensi dan disajikan dalam bentuk tabeldan dianalisis secara deskriptif berdasarkan persentase.

\section{HASIL}

Tabel 1. Distribusi subyek penelitian berdasarkan jenis kelamin

\begin{tabular}{lll}
\hline Jenis kelamin & Jumlah (n) & \multicolumn{1}{c}{$\begin{array}{c}\text { Persentase } \\
(\%)\end{array}$} \\
\hline Laki-laki & 37 & 61.67 \\
Perempuan & 23 & 38.33 \\
\hline Total & 60 & 100 \\
\hline
\end{tabular}

Karakteristik subyek penelitian pada anak-anak sekolah dasar kelas VI di desa
Kiawa usia 10-11 tahun dengan jumlah subyek yaitu 60 anak yang terdiri dari 37 anak berjenis kelamin laki-laki dan 23 anak berjenis kelamin perempuan. Hasil penelitian menunjukkan subyek berjenis kelamin laki-laki memiliki jumlah lebih banyak daripada subyek berjenis kelamin perempuan (Tabel 1).

Tabel 2. Distribusi subyek penelitian berdasarkan umur

\begin{tabular}{ccc}
\hline Umur & $\begin{array}{c}\text { Jumlah } \\
\text { (n) }\end{array}$ & $\begin{array}{c}\text { Persentase } \\
(\mathbf{\%})\end{array}$ \\
\hline 10 & 38 & 63.33 \\
11 & 22 & 26.67 \\
\hline Total & 60 & 100 \\
\hline
\end{tabular}

Berdasarkan umur subyek yang diteliti menunjukkan antara usia 10-11 tahun, terdapat 38 anak yang berumur 10 tahun dan 22 anak berumur 11 tahun. Hasil penelitian menunjukkan subyek berumur 10 tahun memiliki jumlah persentase lebih banyak daripada subyek berumur 11 tahun (Tabel 2).

Tabel 3. Distribusi jenis pekerjaan orang tua responden

\begin{tabular}{|c|c|c|c|c|}
\hline \multirow{3}{*}{$\begin{array}{l}\text { Jenis } \\
\text { pekerjaan }\end{array}$} & \multicolumn{4}{|c|}{ Orang tua } \\
\hline & \multicolumn{2}{|c|}{ Ayah } & \multicolumn{2}{|c|}{ Ibu } \\
\hline & $\mathrm{n}$ & $\%$ & $\mathrm{n}$ & $\%$ \\
\hline $\begin{array}{l}\text { Ibu rumah } \\
\text { tangga }\end{array}$ & 0 & 0 & 39 & 65 \\
\hline Wiraswasta & 27 & 45 & 11 & 18.33 \\
\hline Petani & 12 & 20 & 4 & 6.67 \\
\hline Supir & 10 & 16.67 & 0 & 0 \\
\hline Tukang & 7 & 11.67 & 0 & 0 \\
\hline PNS & 3 & 53 & 5 & 8.33 \\
\hline TKW & 0 & 0 & 1 & 1.67 \\
\hline Lain-lain & 1 & 1.67 & 2 & 3.33 \\
\hline Total & 60 & 100 & 60 & 100 \\
\hline
\end{tabular}

Tabel 3 menunjukkan jenis pekerjaan orangtua subyek sebagian besar pekerjaan sebagai ibu rumah tangga yaitu sebanyak 39 
62 Jurnal e-GiGi (eG), Volume 1, Nomor 1, Maret 2013, hlm. 59-68

orang (65\%) untuk pekerjaan ibu dan pekerjaan ayah sebagai wiraswasta sebanyak 27 orang (45\%).

Tabel 4. Distribusi pengalaman karies masingmasing komponen DMF-T

\begin{tabular}{ccccc}
\hline \multicolumn{3}{c}{ DMF-T } & \multirow{2}{*}{ Jumlah } & Rata-rata \\
D & M & F & DMF-T \\
\hline 189 & 34 & 0 & 223 & 3.71 \\
\hline
\end{tabular}

Hasil pemeriksaan penelitian pengalaman karies gigi pada anak sekolah dasar kelas VI usia 10-11 tahun di desa Kiawa yang berjumlah 60 orang memiliki jumlah DMF-T 223 dan rata-rata DMF-T yaitu 3.71. Hasil ini menunjukkan anak-anak sekolah dasar di desa kiawa memiliki pengalaman karies gigi kategori sedang (Tabel 4).

Tabel 5. Distribusi pengalaman karies berdasarkan jenis kelamin

\begin{tabular}{|c|c|c|c|c|c|}
\hline \multirow{2}{*}{$\begin{array}{c}\text { Jenis } \\
\text { kelamin }\end{array}$} & \multicolumn{3}{|c|}{ DMF-T } & \multirow{2}{*}{ Jumlah } & \multirow{2}{*}{$\begin{array}{c}\text { Rata-rata } \\
\text { DMF-T }\end{array}$} \\
\hline & $\mathrm{D}$ & $\mathrm{M}$ & $\mathrm{F}$ & & \\
\hline Laki-laki & 119 & 24 & 0 & 143 & 3.86 \\
\hline $\begin{array}{l}\text { Perem- } \\
\text { puan }\end{array}$ & 70 & 10 & 0 & 80 & 3.47 \\
\hline
\end{tabular}

Hasil penelitian pada Tabel 5 menunjukkan pengalaman karies gigi pada anak-anak sekolah dasar kelas VI di desa Kiawa berdasarkan jenis kelamin menunjukkan anak-anak sekolah berjenis kelamin laki-laki memiliki jumlah DMFT143 dengan rata-rata DMF-T 3.86 dan anak-anak-sekolah berjenis kelamin perempuan memiliki junlah DMF-T 80 dengan rata-rata DMF-T 3.47

Tabel 6. Distribusi pengalaman karies gigi berdasarkan umur

\begin{tabular}{cccccc}
\hline Umur & \multicolumn{3}{c}{ DMF-T } & Jumlah & $\begin{array}{c}\text { Rata-rata } \\
\text { DMF-T }\end{array}$ \\
\cline { 2 - 4 } & $\mathrm{D}$ & $\mathrm{M}$ & $\mathrm{F}$ & $\mathrm{n}$ & \\
10 & 108 & 16 & 0 & 124 & 3.86 \\
11 & 77 & 8 & 0 & 85 & 3.47 \\
\hline
\end{tabular}

Pengalaman karies gigi berdasarkan umur anak-anak sekolah dasar kelas VI yaitu tertingi pada subyek penelitian umur 10 tahun dengan jumlah 124 dan rata-rata DMF-T 3.86. Subyekberumur 11 tahun berjumlah 85 dengan rata-rata DMF-T 3.47.

Hasil penelitian tentang pola makan pada anak-anak SD di desa Kiawa Kecamatan Kawangkoan yaitu anak-anak yang memiliki kebiasaan mengonsumsi makanan non kariogenik dengan (Tabel 6).

Tabel 7. Distribusi frekuensi pola makan makanan non kariogenik per hari

\begin{tabular}{|c|c|c|c|c|c|c|c|c|c|c|}
\hline \multirow{4}{*}{$\begin{array}{l}\text { Jenis makanan } \\
\text { non kariogenik }\end{array}$} & \multicolumn{6}{|c|}{ Frekuensi Pola Makan } & \multirow{3}{*}{\multicolumn{2}{|c|}{$\begin{array}{l}\text { Tidak } \\
\text { Pernah }\end{array}$}} & \multirow{3}{*}{\multicolumn{2}{|c|}{ Jumlah }} \\
\hline & \multicolumn{6}{|c|}{ Hari } & & & & \\
\hline & \multicolumn{2}{|c|}{1 kali } & \multicolumn{2}{|c|}{ 2-3 kali } & \multicolumn{2}{|c|}{$>3$ kali } & & & & \\
\hline & $\mathrm{n}$ & $\%$ & $\mathrm{n}$ & $\%$ & $\mathrm{n}$ & $\%$ & $\mathrm{n}$ & $\%$ & $\mathrm{n}$ & $\%$ \\
\hline Nasi & 0 & 0 & 48 & 80 & 12 & 20 & 0 & 0 & 60 & 100 \\
\hline Jagung & 3 & 5 & 6 & 10 & 1 & 1.67 & 13 & 21.66 & 23 & 38.33 \\
\hline Mie Instan & 3 & 5 & 20 & 33.33 & 1 & 1.67 & 1 & 1.67 & 25 & 41.67 \\
\hline Kentang & 2 & 3.33 & 8 & 13.33 & 3 & 5 & 6 & 10 & 19 & 31.66 \\
\hline Ubi jalar & 4 & 6.66 & 8 & 13.33 & 2 & 3.33 & 9 & 15 & 23 & 38.33 \\
\hline Singkong & 3 & 5 & 8 & 13.33 & 0 & 0 & 6 & 10 & 17 & 28.33 \\
\hline Sayuran & 2 & 3.33 & 27 & 45 & 11 & 18.33 & 1 & 1.67 & 41 & 68.33 \\
\hline Kacang-kacangan & 3 & 5 & 11 & 18.33 & 2 & 3.33 & 5 & 8.33 & 21 & 35 \\
\hline Buah-buahan & 7 & 11.66 & 17 & 28.33 & 7 & 11.66 & 0 & 0 & 31 & 51.66 \\
\hline
\end{tabular}


Tabel 8. Distribusi frekuensi pola makan makanan kariogenik per-hari

\begin{tabular}{|c|c|c|c|c|c|c|c|c|c|c|}
\hline \multirow{4}{*}{$\begin{array}{c}\text { Jenis } \\
\text { makanan } \\
\text { kariogenik }\end{array}$} & \multicolumn{6}{|c|}{ Frekuensi pola makan } & \multirow{3}{*}{\multicolumn{2}{|c|}{$\begin{array}{c}\text { Tidak } \\
\text { pernah }\end{array}$}} & \multirow{2}{*}{\multicolumn{2}{|c|}{ Jumlah }} \\
\hline & \multicolumn{6}{|c|}{ Hari } & & & & \\
\hline & \multicolumn{2}{|c|}{1 kali } & \multicolumn{2}{|c|}{$2-3$ kali } & \multicolumn{2}{|c|}{$>3$ kali } & & & & \\
\hline & $\mathrm{n}$ & $\%$ & $\mathrm{n}$ & $\%$ & $\mathrm{n}$ & $\%$ & $\mathrm{n}$ & $\%$ & $n$ & $\%$ \\
\hline Roti & 9 & 15 & 13 & 21.66 & 4 & 6.66 & 5 & 8.33 & 31 & 51.66 \\
\hline Kue & 10 & 16.66 & 9 & 15 & 3 & 5 & 4 & 6.66 & 26 & 43.33 \\
\hline Permen & 3 & 5 & 17 & 28.33 & 19 & 31.66 & 3 & 5 & 42 & 70 \\
\hline Coklat & 7 & 11.66 & 14 & 23.33 & 6 & 10 & 5 & 8.33 & 32 & 53.33 \\
\hline Snack & 7 & 11.66 & 20 & 33.33 & 12 & 20 & 5 & 8.33 & 44 & 73.33 \\
\hline
\end{tabular}

persentase terbesar pada 48 anak (80 \%) yang memiliki kebiasaan makan nasi 2-3 kali dalam sehari. Persentase terbesar pola makan jagung yaitu terdapat 13 anak (21.66\%) menyatakan tidak pernah mengonsumsi jagung, tetapi terdapat 5 anak yang mengonsumsi jagung setiap hari dengan frekuensi waktu 2-3 kali dalam sehari. Anak-anak sekolah memiliki kebiasaan mengonsumsi jagung lebih banyak yaitu pada frekuensi waktu 1 kali dalam seminggu (Tabel 10). Persentase terbesar pola makan mie instan yaitu terdapat 20 anak (33.33\%) yang memiliki kebiasaan mengonsumsi mie instan 2-3 kali per hari. Pola makan kentang dengan persentase terbesar 2-3 kali per hari yaitu terdapat 8 anak (13.33\%). Persentase terbesar pola makan singkong dengan persentase terbesar 2-3 kali per hari yaitu 8 anak (13.33\%) yang mengonsumsi singkong (Tabel 7).

Persentase terbesar pada pola makan makanan kariogenik seperti roti, kue, permen dan coklat yaitu terdapat 13 anak (21.66\%) yang memiliiki kebiasaan mengonsumsi roti pada frekuensi waktu 2-3 kali per hari.Sebanyak 5 orang anak (8.33\%) yang tidak memiliki kebiasaan mengonsumsi roti. Persentase terbesar pola makan kue yaitu terdapat 8 anak (13.33\%) yang mengonsumsi kue 2-3 kali per hari. Jumlah anak yang tidak pernah mengonsumsi kue yaitu sebanyak 4 orang (6.66\%). Pola makan permen dengan persentase terbesar yaitu terdapat 19 anak (31.66\%) yang memiliki kebiasaan mengonsumsi permen $>3$ kali per hari. Anak-anak sekolah yang menyatakan tidak pernah mengonsumsi permen yaitu terdapat 3 orang (5\%). Persentase terbesar pola makan coklat dengan kebiasaan mengonsumi coklat 2-3 kali per hari terdapat pada 14 anak (23.33\%). Anak-anak sekolah yang menyatakan tidak pernah mengonsumsi coklat yaitu terdapat 5 orang anak (8.33\%). Persentase terbesar pola makan snack 2-3 kali per hari yaitu 20 anak (33.33\%). Jumlah anak-anak yang tidak pernah makan snack yaitu terdapat 5 anak (8.33\%). Pola makan sayuran dengan persentase terbesar 2-3 kali per hari yaitu terdapat 27 anak (45\%). Anak sekolah yang memiliki kebiasaan tidak pernah mengonsumsi sayur yaitu hanya terdapat 1 orang anak (1.67\%). Pola konsumsi kacangkacangan dengan persentase terbesar yaitu terdapat 11 anak(18.33) yang mengonsumsi kacang-kacangan dengan frekuensi waktu 23 kali dalam sehari. Jumlah anak yang tidak pernah mengonsumsi kacang-kacangan yaitu 5 orang anak (8.33\%). Persentase terbesar pola makan buah-buahan 2-3 kali dalam sehari yaitu terdapat 17 anak (28.33\%) yang menyatakan memiliki kebiasaan mengonsumsi buah-buahan (Tabel 8).

Pola makan dalam seminggu yaitu menunjukkan terdapat 21 anak (35\%) mengonsumsi jagung 1 kali seminggu. Pola makan mie instan yaitu terdapat 19 anak (31.66\%) mengonsumsi dalam waktu 2-3 kali seminggu. 
64 Jurnal e-GiGi (eG), Volume 1, Nomor 1, Maret 2013, hlm. 59-68

Tabel 9. Distribusi frekuensi pola makan makanan non kariogenik per minggu

\begin{tabular}{|c|c|c|c|c|c|c|c|c|}
\hline \multirow{4}{*}{$\begin{array}{c}\text { Jenis makanan non } \\
\text { kariogenik }\end{array}$} & \multicolumn{6}{|c|}{ Frekuensi pola makan } & \multirow{2}{*}{\multicolumn{2}{|c|}{ Jumlah }} \\
\hline & \multicolumn{6}{|c|}{ Minggu } & & \\
\hline & \multicolumn{2}{|c|}{$1 \mathrm{kali}$} & \multicolumn{2}{|c|}{$2-3$ kali } & \multicolumn{2}{|c|}{ 4-6 kali } & \multirow[b]{2}{*}{$\mathrm{n}$} & \multirow[b]{2}{*}{$\%$} \\
\hline & $\mathrm{n}$ & $\%$ & $\mathrm{n}$ & $\%$ & $\mathrm{n}$ & $\%$ & & \\
\hline Nasi & 0 & 0 & 0 & 0 & 0 & 0 & 0 & 0 \\
\hline Jagung & 21 & 35 & 15 & 25 & 1 & 1.67 & 37 & 61.66 \\
\hline Mie Instan & 17 & 28.33 & 19 & 31.66 & 9 & 15 & 45 & 75 \\
\hline Kentang & 15 & 25 & 22 & 36.66 & 4 & 6.66 & 41 & 68.33 \\
\hline Ubi jalar & 19 & 31.67 & 15 & 25 & 3 & 5 & 37 & 61.67 \\
\hline Singkong & 18 & 30 & 25 & 41.66 & 0 & 0 & 43 & 71.66 \\
\hline Sayuran & 3 & 5 & 11 & 18.33 & 7 & 11.66 & 21 & 35 \\
\hline Kacang-kacangan & 15 & 25 & 20 & 33.33 & 4 & 6.66 & 39 & 65 \\
\hline Buah-buahan & 8 & 13.33 & 15 & 25 & 8 & 13.33 & 31 & 51.66 \\
\hline
\end{tabular}

Tabel 10. Distribusi frekuensi pola makan makanan kariogenik per minggu

\begin{tabular}{|c|c|c|c|c|c|c|c|c|}
\hline \multirow{4}{*}{$\begin{array}{c}\text { Jenis makanan } \\
\text { kariogenik }\end{array}$} & \multicolumn{6}{|c|}{ Frekuensi pola makan } & \multirow{2}{*}{\multicolumn{2}{|c|}{ Jumlah }} \\
\hline & \multicolumn{6}{|c|}{ Minggu } & & \\
\hline & \multicolumn{2}{|c|}{1 kali } & \multicolumn{2}{|c|}{ 2-3 kali } & \multicolumn{2}{|c|}{ 4-6 kali } & \multirow[b]{2}{*}{$\mathrm{n}$} & \multirow[b]{2}{*}{$\%$} \\
\hline & $\mathrm{n}$ & $\%$ & $\mathrm{n}$ & $\%$ & $\mathrm{n}$ & $\%$ & & \\
\hline Roti & 4 & 6.66 & 17 & 28.33 & 5 & 8.33 & 26 & 43.33 \\
\hline Kue & 13 & 21.66 & 16 & 26.66 & 5 & 8.33 & 37 & 61.67 \\
\hline Permen & 5 & 8.33 & 6 & 10 & 7 & 11.66 & 18 & 30 \\
\hline Coklat & 14 & 23.33 & 11 & 18.33 & 3 & 5 & 28 & 46.66 \\
\hline Snack & 7 & 11.66 & 6 & 10 & 3 & 5 & 16 & 26.66 \\
\hline
\end{tabular}

Tabel 11. Distribusi frekuensi pola minum minuman non kariogenik per hari

\begin{tabular}{|c|c|c|c|c|c|c|c|c|c|c|}
\hline \multirow{4}{*}{$\begin{array}{c}\text { Jenis } \\
\text { minuman non } \\
\text { kariogenik }\end{array}$} & \multicolumn{6}{|c|}{ Frekuensi Pola Minum } & \multirow{3}{*}{\multicolumn{2}{|c|}{$\begin{array}{c}\text { Tidak } \\
\text { Pernah }\end{array}$}} & \multirow{2}{*}{\multicolumn{2}{|c|}{ Jumlah }} \\
\hline & \multicolumn{6}{|c|}{ Hari } & & & & \\
\hline & \multicolumn{2}{|c|}{1 kali } & \multicolumn{2}{|c|}{ 2-3 kali } & \multicolumn{2}{|c|}{$>3$ kali } & & & & \\
\hline & $\mathrm{n}$ & $\%$ & $\mathrm{n}$ & $\%$ & $\mathrm{n}$ & $\%$ & $\mathrm{n}$ & $\%$ & $\mathrm{n}$ & $\%$ \\
\hline Air putih & 0 & 0 & 10 & 16.66 & 50 & 68.33 & 0 & 0 & 60 & 100 \\
\hline Susu murni & 8 & 13.33 & 14 & 23.33 & 0 & 0 & 9 & 15 & 31 & 51.66 \\
\hline Teh murni & 14 & 23.33 & 26 & 43.33 & 1 & 1.67 & 5 & 8.33 & 46 & 76.67 \\
\hline Kopi murni & 7 & 11.66 & 6 & 10 & 1 & 1.67 & 21 & 35 & 35 & 58.33 \\
\hline Sirup murni & 6 & 10 & 3 & 5 & 0 & 0 & 32 & 53.33 & 41 & 68.33 \\
\hline Jus buah murni & 5 & 8.33 & 3 & 5 & 0 & 0 & 33 & 55 & 41 & 68.33 \\
\hline
\end{tabular}


Pola makan kentang terdapat 22 anak (36.66\%) mengonsumsi kentang 2-3 kali seminggu. Pola makan ubi jalar yaitu terdapat 19 anak (31.66\%) mengonsumsi 1 kali seminggu. Pola makan singkong terdapat 25 anak (41.66\%) mengonsumsi 23 kali seminggu. Pola makan sayuran terdapat 11 anak (18.33\%) mengonsumsi 2-3 kali. Persentase terbesar pola makan kacangkacangan yaitu 15 anak (25\%) mengonsumsi kacang-kacangan 1 kali dalam seminggu. Buah-buahan dengan persentase terbesar pola makanyaitu 15 anak (25\%) memiliki kebiasaan mengonsumsi 2-3 kali (Tabel 9).

Pola makan roti terdapat 17 anak (28.33\%) mengonsumsi 2-3 kali seminggu. Polamakan kue terdapat 16 anak (26.66\%) yaitu 2-3 kali seminggu. Persentase terbesar pola makan permen yaitu terdapat 7 anak (11.66\%) mengonsumsi 4-6 kali dalam seminggu. Pola makan coklat terdapat 14 anak (23.33\%) yaitu 1 kali seminggu. Persentase terbesar pola makan snack terdapat 7 anak (11.66\%) yaitu mengonsumsi 1 kali dalam seminggu (Tabel 10)

Tabel 11 menunjukkan frekuensi pola minum minuman non kariogenik setiap hari pada anak-anak SD kelas VI. Sebanyak 50 anak (68.33\%) minum air putih $>3$ kali sehari. Pola minum susu murni terdapat 14 anak (23.33\%) mengonsumsi 2-3 kali sehari.
Teh murni dikonsumsi oleh 26 anak (43.33\%) 2-3 kali sehari. Pola minum kopi murni terdapat 21 anak (35\%) tidak pernah mengonsumsi kopi murni. Persentase terbesar untuk sirup murni terdapat 32 anak (53.33\%) tidak pernah mengonsumsi minuman tersebut. Pola minum jus buah murni terdapat 33 anak (55\%) tidak pernah mengonsumsi jus buah murni.

Tabel 12 menunjukkan jumlah anakanak sekolah dasar kelas VI di desa kiawa yang memiliki kebiasaan mengonsumsi jenis minuman kariogenik. Sebanyak 18 anak (30\%) minum susu kemasan 2-3 kali. Persentase terbesar pola minum teh kemasan yaitu 17 anak (11.66\%) tidak pernah mengonsumsi minuman tersebut. Sedangkan persentase terbesar untuk kopi kemasan terdapat 32 anak (53.33\%) tidak pernah mengonsumsi kopi kemasan. Sirup kemasan sebanyak 16 anak (26.66\%) mengonsumsi 2-3 kali sehari. Jus buah kemasan sebanyak 16 anak (26.66\%) juga tidak pernah mengonsumsi jus buah kemasan. Persentase terbesar untuk ice cream terdapat 15 anak (25\%) mengonsumsi 2-3 kali sehari. Soft drink sebanyak 8 anak (13.33) mengonsumsi 2-3 kali sehari. Persentase terbesar pola minum minuman isotonik terdapat 12 anak (20\%) tidak pernah mengonsumsi minuman tersebut.

Tabel 12. Distribusi frekuensi pola minum minuman kariogenik per hari

\begin{tabular}{|c|c|c|c|c|c|c|c|c|c|c|}
\hline \multirow{4}{*}{$\begin{array}{l}\text { Jenis minuman } \\
\text { kariogenik }\end{array}$} & \multicolumn{6}{|c|}{ Frekuensi pola minum } & \multirow{3}{*}{\multicolumn{2}{|c|}{$\begin{array}{l}\text { Tidak } \\
\text { pernah }\end{array}$}} & \multirow{2}{*}{\multicolumn{2}{|c|}{ Jumlah }} \\
\hline & \multicolumn{6}{|c|}{ Hari } & & & & \\
\hline & \multicolumn{2}{|c|}{1 kali } & \multicolumn{2}{|c|}{ 2-3 kali } & \multicolumn{2}{|c|}{$>3$ kali } & & & & \\
\hline & $\mathrm{n}$ & $\%$ & $n$ & $\%$ & $\mathrm{n}$ & $\%$ & $\mathrm{n}$ & $\%$ & $\mathrm{n}$ & $\%$ \\
\hline Teh kemasan & 5 & 8.33 & 8 & 13.33 & 2 & 3.33 & 17 & 28.33 & 32 & 53.33 \\
\hline Kopi kemasan & 4 & 6.66 & 3 & 5 & 0 & 0 & 32 & 53.33 & 39 & 65 \\
\hline Susu kemasan & 6 & 10 & 18 & 30 & 1 & 1.67 & 6 & 10 & 23 & 38.33 \\
\hline Sirup kemasan & 7 & 11.66 & 16 & 26.66 & 3 & 5 & 17 & 28.33 & 36 & 60 \\
\hline $\begin{array}{l}\text { Jus buah } \\
\text { kemasan }\end{array}$ & 9 & 15 & 9 & 15 & 6 & 10 & 16 & 26.66 & 40 & 66.66 \\
\hline Ice cream & 8 & 13.33 & 15 & 25 & 2 & 3.33 & 1 & 1.67 & 26 & 43.33 \\
\hline $\begin{array}{l}\text { Soft drink } \\
\text { Minuman }\end{array}$ & 5 & 8.33 & 8 & 13.33 & 0 & 0 & 5 & 8.33 & 18 & 30 \\
\hline isotonik & 6 & 10 & 5 & 8.33 & 0 & 0 & 12 & 20 & 23 & 38.33 \\
\hline
\end{tabular}


66 Jurnal e-GiGi (eG), Volume 1, Nomor 1, Maret 2013, hlm. 59-68

Tabel 13. Distribusi frekuensi pola minum minuman non kariogenik per minggu

\begin{tabular}{|c|c|c|c|c|c|c|c|c|}
\hline \multirow{3}{*}{ Jenis minuman } & \multicolumn{6}{|c|}{$\begin{array}{c}\text { Frekuensi Pola Minum } \\
\text { Minggu }\end{array}$} & \multicolumn{2}{|c|}{ Jumlah } \\
\hline & \multicolumn{2}{|c|}{ 1-3 kali } & \multicolumn{2}{|c|}{ 4-6 kali } & \multicolumn{2}{|c|}{$>6$ kali } & \multirow[b]{2}{*}{$\mathrm{n}$} & \multirow[b]{2}{*}{$\%$} \\
\hline & $\mathrm{n}$ & $\%$ & $\mathrm{n}$ & $\%$ & $\mathrm{n}$ & $\%$ & & \\
\hline Air putih & 0 & 0 & 0 & 0 & 0 & 0 & 0 & 0 \\
\hline Susu murni & 11 & 18.33 & 14 & 23.33 & 4 & 6.66 & 29 & 48.33 \\
\hline Teh murni & 4 & 6.66 & 7 & 11.66 & 3 & 5 & 14 & 23.33 \\
\hline Kopi murni & 14 & 23.33 & 9 & 15 & 2 & 3.33 & 25 & 41.66 \\
\hline Sirup murni & 8 & 13.33 & 6 & 10 & 5 & 8.33 & 19 & 31.66 \\
\hline Jus buah murni & 10 & 16.66 & 8 & 13.33 & 1 & 1.67 & 19 & 31.66 \\
\hline
\end{tabular}

Tabel 14. Distribusi frekuensi pola minum minuman kariogenik per minggu

\begin{tabular}{|c|c|c|c|c|c|c|c|c|}
\hline \multirow{4}{*}{$\begin{array}{l}\text { Jenis minuman } \\
\text { karioegenik }\end{array}$} & \multicolumn{6}{|c|}{ Frekuensi pola minum } & \multirow{2}{*}{\multicolumn{2}{|c|}{ Jumlah }} \\
\hline & \multicolumn{6}{|c|}{ Minggu } & & \\
\hline & \multicolumn{2}{|c|}{ 1-3 kali } & \multicolumn{2}{|c|}{ 4-6 kali } & \multicolumn{2}{|c|}{$>6$ kali } & & \\
\hline & $\mathrm{n}$ & $\%$ & $\mathrm{n}$ & $\%$ & $\mathrm{n}$ & $\%$ & $\mathrm{n}$ & $\%$ \\
\hline Susu kemasan & 10 & 16.66 & 14 & 23.33 & 5 & 8.33 & 29 & 48.33 \\
\hline Teh kemasan & 11 & 18.33 & 12 & 20 & 5 & 8.33 & 28 & 46.66 \\
\hline Kopi kemasan & 12 & 20 & 9 & 15 & 0 & 0 & 21 & 35 \\
\hline Sirup kemasan & 5 & 8.33 & 10 & 16.66 & 2 & 3.33 & 17 & 28.33 \\
\hline Jus buah kemasan & 12 & 20 & 11 & 18.33 & 0 & 0 & 23 & 38.33 \\
\hline Ice cream & 13 & 21.66 & 19 & 31.66 & 2 & 3.33 & 34 & 56.66 \\
\hline Soft drink & 17 & 28.33 & 20 & 33.33 & 5 & 8.33 & 42 & 70 \\
\hline Minuman isotonik & 22 & 36.66 & 13 & 21.66 & 2 & 3.33 & 37 & 61.66 \\
\hline
\end{tabular}

Frekuensi pola minum jenis minuman non kariogenik dalam seminggu pada Tabel 13, persentase terbesar konsumsi susu murni yaitu 14 anak (23.33\%) 4-6 kali seminggu. Teh murni sebanyak 7 anak (11.66\%) mengonsumsi 4-6 kali seminggu. Kopi murni sebesar 23.33\% yaitu 14 anak mengonsumsi 1-3 kali seminggu. Sirup murni sebanyak 8 anak (13.33\%) mengonsumsi 1-3 kali seminggu. Jus buah murni dikonsumsi 10 anak (16.66\%) 1-3 kali seminggu.

Tabel 14 menunjukkan pola minuman kariogenik dalam seminggu yaitu susu kemasan terdapat sebanyak 14 anak (23.33\%) 4-6 kali. Persentase terbesar pola konsumsi teh kemasan yaitu 12 anak (20\%) 4-6 kali seminggu. Kopi kemasan sebesar 20\% yaitu 12 anak mengonsumsi 1-3 kali seminggu. Sebanyak 10 anak (16.66\%) mengonsumsi sirup kemasan $>6$ kali seminggu. Jus buah kemasan dikonsumsi 1-
3 kali seminggu sebanyak 12 anak (20\%). Persentase sebesar $31.66 \%$ yaitu 19 anak mengonsumsi ice cream4-6 kali seminggu. Sebanyak 20 anak (33.33\%) mengonsumsi soft drink 4-6 kali seminggu. Minuman isotonik dikonsumsi 22 anak (36.66\%) 1-3 kali seminggu.

\section{BAHASAN}

Berdasarkan jenis kelamin, anak-anak sekolah berjenis kelamin laki-laki memiliki rata-rata DMF-T lebih tinggi daripada anak berjenis kelamin perempuan yaitu 3.86 dengan tingkat karies kategori sedang. Hal ini disebabkan lebih banyak anak perempuan yang memiliki kebiasaan menyikat gigi sebelum tidur. Penelitian yang dilakukan oleh Joshi pada tahun 2005 di India dari total populasi 150 orang diperoleh kejadian 
karies lebih tinggi pada laki-laki yaitu 80\%, sedangkan wanita 73\%. [Suwargiawan, 2008] Sama halnya dengan hasil penelitian yang dilakukan oleh Nurhaida di Makassar tahun 2011 yaitu peroleh rata-rata DMF-T pada laki-laki lebih tinggi (3.15) dibandingkan rata-rata DMF-T pada perempuan (2.82). Hal ini terjadi dikarenakan wanita lebih memiliki keinginan untuk menjaga kebersihannya. [Lamlanto M, 2011]

Hasil penelitian karies gigi pada anak SD kelas VI usia 10-11 tahun di desa Kiawa berdasarkan kategori umur, jumlah DMF-T lebih banyak pada umur 10 tahun yaitu 124 dengan rata-rata DMF-T 3.86, tingkat karies kategori sedang. Jumlah DMF-T pada anak umur 11 tahun yaitu 85 dengan rata-rata DMF-T 3.47, dengan tingkat karies kategori sedang. Hasil ini menunjukkan bahwa kejadian karies pada kedua kelompok usia tersebut memiliki pengalaman karies gigi yang sama. Kejadian ini juga bisa dipengaruhi oleh beberapa faktor lain seperti kebersihan gigi dan mulut, serta pemilihan makanan yang dikonsumsi yang dapat menyebabkan terjadinya karies gigi.

Berdasarkan hasil pemeriksaan karies pada anak-anak sekolah dasar usia 10-11 tahun di desa Kiawa memiliki pengalaman karies gigi dengan rata-rata DMF-T 3.71. Hasil tersebut menunjukkan pengalaman karies gigi pada anak-anak SD di desa Kiawa memiliki tingkat karies kategori sedang. Penelitian yang sama juga dilakukan oleh Meilyana Hartikapada anak-anak sekolah usia 10-11 tahun di SD N Maccini Makasar di bulan Februari 2012. Hasil yang diperoleh rata-rata DMFT yakni 2,36 termasuk kategori sedang. [Meilyana H,2012] Setiap komponen DMF-T, karies gigi, sisa akar (decay) memiliki jumlah terbanyak, sedangkan filling (F) tidak ada, karena tidak didapati gigi yang ditambal pada anak-anak sekolah tersebut. Hal ini disebabkan kurangnya perhatian orang tua dalam merawat kesehatan gigi dan mulut anaknya sehingga anak-anak tersebut tidak pernah memeriksakan gigi dan mulut ke dokter gigi. Hal lain yang berhubungan dengan itu yaitu pengetahuan tentang menjaga kebersihan gigi dan mulut masih kurang karena sekolah-sekolah dasar di desa Kiawa belum pernah dilakukan penyuluhan tentang kesehatan gigi dan mulut serta program UKGS yang belum dilaksanakan.

Hasil penelitian mengenai pola makan anak-anak SD setiap harinya dengan persentase terbesar pola makan nasi 2-3 kali dalam sehari yaitu 48 anak (80\%). Beras (nasi) di dalam hidangan di Indonesia merupakan sumber utama energi dan protein. Bahan makanan pokok bagi sebagian masyarakat Indonesia ini banyak dimanfaatkan sebagai sumber karbohidrat bagi tubuh.[Hawkins RJ, 2000] Jenis karbihidrat lain seperti kentang, singkong, ubi jalar merupakan jenis makanan yang biasa juga dikonsumsi oleh anak-anak sekolah dengan frekuensi waktu 2-3 kali dalam sehari. Hal ini disebabkan umumnya masyarakat di desa Kiawa memiliki sawah dan kebun, sehingga lewat hasil pertanian dan perkebunan tersebut banyak dimanfaatkan oleh masyarakat dalam memenuhi kebutuhan pangannya.

Pola makan makanan kariogenik dengan persentase terbesar pola makan permenyaitu terdapat 19 anak (31.66\%) mengonsumsi permen $>3$ kali per hari. Kebiasaan mengonsumsi Snackbanyak dilakukan oleh anak-anak sekolah yaitu sebanyak 20 anak dengan frekuensi waktu konsumsi yaitu 2-3 kali per hari. Hal ini disebabkan anak-anak sekolah yang menyukai makanan yang manis dan memiliki bermacam-macam rasa.

Pola makan makanan non kariogenik yaitu sayuran dengan persentase terbesar yaitu terdapat 27 anak (45\%) yang mengonsumsi sayuran 2-3 kali per hari. Frekuensi pola makan per minggu yaitu sebanyak 25 anak (41.66\%) mengonsumsi singkong dengan waktu 2-3 kali per minggu. Hasil penelitian pola minum setiap hari pada anak-anak SD kelas VI. Persentase terbesar yaitu sebanyak 50 anak (68.33\%) mengonsumsi minuman air putih $>3 \mathrm{kali}$ sehari. Persentase terbesar untuk pola minum minuman sirup murni terdapat 32 anak (53.33\%) tidak pernah mengonsumsi minuman tersebut.Pola minum jus buah 
murni yaitu terdapat 33 anak (55\%) tidak pernah mengonsumsi jus buah murni.

Persentase terbesar pada pola minum minuman non kariogenik untuk kopi kemasan yaitu terdapat 32 anak (53.33\%) tidak pernah mengonsumsi kopi kemasan. Pola minum sirup kemasan memiliki persentase sebesar $26.66 \%$ yaitu terdapat 16 anak mengonsumsi 2-3 kali sehari. Frekuensi pola minum per minggu yaitu sebanyak 22 anak (36.66\%) mengonsumsi minuman isotonik dengan waktu 1 kali dalam seminggu.

\section{SIMPULAN}

1. Anak-anak sekolah dasar memiliki pengalaman karies gigi kategori sedang dengan jumlah rata-rata DMF-T yaitu 3,71 yang artinya anak-anak rata-rata mengalami karies empat gigi.

2. Pola makan makanan karbohidrat kariogenik tertinggi pada anak sekolah dasar yaitu snackpada frekuensi waktu 2-3 kali per hari.

3. Pola minum minuman kariogenik tertinggi pada anak sekolah dasar yaitu minuman isotonikpada frekuensi 1-3 kali per minggu.

\section{SARAN}

1. Bagi pihak sekolah agar lebih memperhatikan tentang kesehatan kepada anakanak sekolah dasar dengan cara melaksanakan program UKS dan UKGS sehingga mereka dapat memiliki pengetahuan, dan keterampilan untuk hidup bersih dan sehat serta menjaga kebersihan gigi dan mulut.

2. Bagi anak-anak sekolah agar terus menjaga kesehatan dan kebersihan gigi dan mulut dengan mengurangi konsumsi makanan manis dan minuman yang dapat merusak gigi. Rajin mengonsumsi makanan dan minuman yang sehat dan bergizi agar gigi dan tubuh tetap sehat dan kuat.

\section{DAFTAR PUSTAKA}

1. Gambaran Karies Gigi Pada Anak. Ebook Kedokteran [homepage on the Internet]. 2012 [cited 2012 Mei 14. Available from: URL:http://www.ebookkedokteran.com/pdf/ gambaran-gigi-karies-pada-anak-anak.html

2. Riskesdas 2007 [homepage on the Internet]. 2007 [cited 2012 Sep 22]. Available from: http://www.google.co.id/ url?sa=t\&rct=j\&q=prevalensi+karies + gigi + pada+anak+sekolah+dasar+di+sulawesi+uta ra\&source $=$ web $\&$ cd $=10 \&$ cad $=$ rja $\& v e d=0 C$ FUQFjAJ\&url=http\%3A\%2F\%2Fwww.ppi d.depkes.go.id\%2Findex.php. h.176

3. Sutrisno K. Makanan Bergula Dan Kerusakan Gigi. Jurnal Karies Gigi Anak [serial online]. 2012 [cited 2012 Mar 20]. Available from: URL:http://www. Ebookpangan.com. h.11

4. Arvin B. Karies Gigi pada Anak [homepage on the Internet]. 2012 [cited 2012 Mar 24]. Available from: URL:hhtp://ilmukesehatangigi.com.

5. Ami A. Pencegahan Primer Pada Anak Yang Berisiko Karies Tinggi. Fakultas Kedokteran Gigi Departemen Pedodonsia Universitas Sumatera Utara [Skripsi]. Medan: USU; 2005.

6. Kidd EAM, Bechal SJ. Dasar-Dasar Karies-Penyakit dan Penanggulangan. Jakarta: Buku Kedokteran EGC, 2012; p.2.

7. Lamlanto M. Hubungan antara status karies gigi dengan status gizi [Skripsi]. Makassar: FKG Unhas; 2011; p.6.

8. Meilyana H. Gambaran kualitas hidup anak usia 10-11 tahun berdasarkan status kesehatan [Skripsi]. Makassar: Universitas Hassanudin; 2012.

9. Hawkins RJ. Oral hygiene knowledge of high risk grade one children: an evaluation of two methods of dental health education. $\mathrm{J}$ community Dentistry and Epidemiology. 2000:228.

10. Sungkar S, Suhendrianto, Fitriyani S. Pengaruh paparan minuman ringan rasa buah secara in vitro terhadap kekasaran permukaan email gigi tetap. Fakultas Kedokteran Unsyiah; 2010; p.96.

11. Nurhayati S. Hubungan mengunyah buah apel sebagai self cleansing effect dengan Debris Index pada siswa MI N Mulur Kecamatan Bendosari Kabupaten Sukoharjo [Skripsi]. Semarang: Universitas Negeri Semarang; 2010. 